
the Creative Commons Attribution-NonCommercial-ShareAlike licence $<$ http://creativecommons.org/licenses/by-nc-sa/2.5/ $>$. The written permission of Cambridge University Press must be obtained for commercial re-use.

\title{
Role of the rumen in copper and thiomolybdate absorption
}

\author{
L. Gould and N. R. Kendall* \\ School of Veterinary Medicine and Science, University of Nottingham, Sutton Bonington Campus, Sutton Bonington, \\ Loughborough LE12 5RD, UK
}

\section{Abstract}

The rumen is the site of significant interactions between $\mathrm{Cu}, \mathrm{S}$ and Mo. It also shows reactions between $\mathrm{Cu}, \mathrm{S}$ and $\mathrm{Fe}$. The interaction between Mo and $\mathrm{S}$ results in the formation of thiomolybdates, which in the absence of adequate quantities of rumen $\mathrm{Cu}$ are absorbed into the animal and bind to $\mathrm{Cu}$ in biological compounds. This is the cause of thiomolybdate toxicity, often misleadingly called Cu deficiency. The effects of thiomolybdates being absorbed into the animal are considered, especially how thiomolybdates bind to $\mathrm{Cu}$-containing compounds such as enzymes, decreasing their activity without removing the active Cu component. The sources of Cu, Mo, Fe and S are examined, including the impacts of water and soil on the animal's intake. Within the present review we have been able to provide evidence that: all classes of thiomolybdates are formed in the rumen; in the absence of available Cu all thiomolybdates can be absorbed into the animal rapidly though the rumen wall or via the small intestine; thiomolybdates bind to Cu in biological compounds and are able to cause problems; effects of thiomolybdate are reversible in vivo and in vitro on cessation of thiomolybdate challenge; the tetra-thiomolybdate form is the most potent $\mathrm{Cu}$ binder with decreased potency with decreasing $\mathrm{S}$ in the compound. Fe will exacerbate a thiomolybdate problem but will not directly cause it.

\section{Key words: Thiomolybdate toxicity: Molybdenum: Sulfur: Iron}

The present review will seek to review the research on $\mathrm{Cu}$ and Mo metabolism within the rumen with relevance to thiomolybdate toxicity in ruminant animals. It will demonstrate that the production of thiomolybdates is a clinical problem and actually causes a thiomolybdate toxicity rather than inducing a $\mathrm{Cu}$ deficiency.

The problem of Fe, $\mathrm{S}$ and Mo interactions with $\mathrm{Cu}$ has been a contentious and confused issue in recent times ${ }^{(1-4)}$. Signs attributed to 'clinical $\mathrm{Cu}$ deficiency' in ruminants are usually, in the field, non-specific and 'subclinical' and include: reduced weight gain, decreased food intake, reduced efficiency of food conversion, alteration in hair/wool texture and pigmentation (spectacles around eyes), delayed puberty, reduced conception rate, inhibition of oestrus, swayback. These do not tend to be the contention, but whether they are caused by a 'lock up' of $\mathrm{Cu}$ (induced or secondary $\mathrm{Cu}$ deficiency) or by the toxic effects of thiomolybdates is. However, much of the historical research into this area has been overlooked, hence the requirement for the present review.

The review will be based on the mechanism outlined in Fig. 1 and each stage will be examined individually in order to elucidate the mechanism. Briefly, Mo, S (as sulfate, sulfide or $\mathrm{S}$ amino acids), $\mathrm{Cu}$ and $\mathrm{Fe}$ all enter the rumen via feed, soil, water or supplements. Reactions occur between
Mo and S enabling the formation of thiomolybdate compounds which will readily bind $\mathrm{Cu}$. In the absence of rumen-available $\mathrm{Cu}$ (rumen-labile $\mathrm{Cu}$ ), thiomolybdates are able to be absorbed through the rumen wall and small intestine, allowing them to bind to $\mathrm{Cu}$-containing substances, including enzymes whose activity will be reduced, thus causing clinical problems often quoted as $\mathrm{Cu}$ deficiency, even though it is strictly a thiomolybdate toxicity. Another interaction between $\mathrm{Fe}, \mathrm{S}$ and $\mathrm{Cu}$ will intensify the thiomolybdate problem by making $\mathrm{Cu}$ unavailable to bind to the thiomolybdates. In the absence of Mo and Fe interactions, the absolute dietary requirement for $\mathrm{Cu}$ is very low; experimentally this has been shown to be $<1.6 \mathrm{mg} / \mathrm{kg} \mathrm{DM}^{(5)}$.

\section{What does TCA-soluble and -insoluble copper measure?}

Much of the literature discussed within the present review uses TCA-insoluble fractions as an experimental result. In order to understand this, we need to appreciate what the TCA precipitation is measuring. The TCA precipitation method involves the addition of equal volumes of TCA solution $(5-10 \%)$ to the sample, the precipitate is then removed by filtration or centrifugation and the liquid fraction can be measured by the same methodology as 


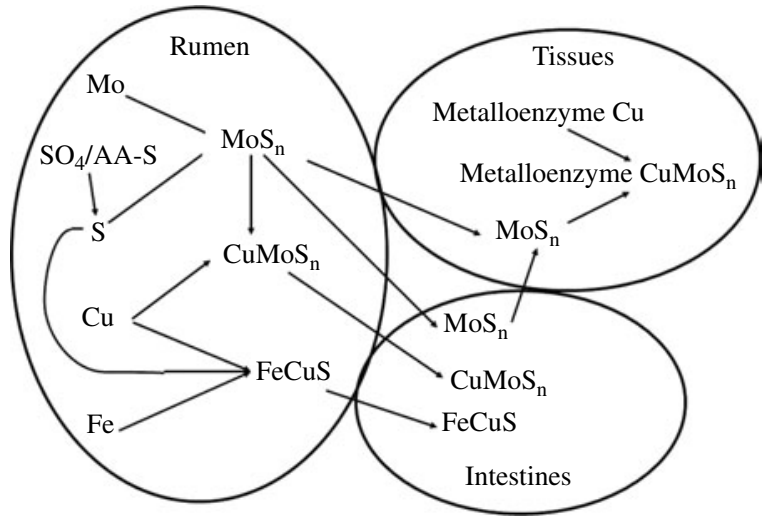

Fig. 1. Ruminal mechanism for the interaction of $\mathrm{Cu}, \mathrm{Mo}, \mathrm{S}$ and $\mathrm{Fe}$ and routes of absorption for the interaction products. $M_{0} S_{n}$ is used diagrammatically to represent the thiomolybdate series $\left(\operatorname{MoS}_{n} \mathrm{O}^{2-}(4-n)\right.$, where $n$ is 1 to 4$)$.

the unprecipitated sample. The TCA-insoluble fraction can either be assessed by difference or by digestion of the precipitate/filtrate.

As early as 1975 , Dick et al. ${ }^{(6)}$ showed that the in vitro addition of increasing amounts of di- $\left(\mathrm{MoS}_{2} \mathrm{O}_{2}^{2-}\right)$, tri$\left(\mathrm{MoS}_{3} \mathrm{O}^{2-}\right)$, or tetra-thiomolybdate $\left(\mathrm{MoS}_{4}^{2-}\right)$, to plasma (which was derived as the filtrate fraction from previous TCA precipitation) resulted in decreased $\mathrm{Cu}$ within the TCA-soluble filtrate until at approximately $3 \mu \mathrm{g} / \mathrm{ml}$ plasma all of the $\mathrm{Cu}$ was found in the TCA precipitate. In vitro addition of molybdate with or without sulfate had no effect on the $\mathrm{Cu}$ in the TCA precipitate. In the absence of thiomolybdates, the $\mathrm{Cu}$ was in the TCA-soluble fraction with $\mathrm{Cu}$ in the TCA precipitate being negligible. This suggested that TCA-insoluble $\mathrm{Cu}$ can be used as an indirect measure of thiomolybdate, differentiating thiomolybdate effects from Mo and S in non-thiomolybdate form.

\section{Are thiomolybdates produced in the rumen?}

Dick et al. ${ }^{(6)}$ showed that duodenal administration of thiomolybdates increased the Cu content in the TCA precipitate of blood plasma, whereas a duodenal infusion of molybdate (with or without S) had no effect whatsoever on the blood plasma TCA-insoluble $\mathrm{Cu}$. This study indicates but does not prove that the thiomolybdate must be absorbed to affect the TCA-insoluble $\mathrm{Cu}$ in plasma and also that thiomolybdates are not formed in the duodenum. A suspension of rumen micro-organisms was incubated in a solution containing molybdate and sulfate; this resulted in the production of a mixture of di-, tri- and tetra-thiomolybdates which were identified by their absorption spectra ${ }^{(6)}$. This led to Dick et al. ${ }^{(6)}$ suggesting the following mechanism: sulfates are first reduced to sulfides by ruminal microorganisms, the sulfide then reacts with the molybdate to form the thiomolybdates, the thiomolybdates then react with $\mathrm{Cu}$ to form insoluble $\mathrm{Cu}$ thiomolybdates, thus limiting the absorption of dietary $\mathrm{Cu}$. In the field, situations with high dietary or water sulfides often have exacerbated 'copper' problems. The reduction of sulfate to sulfide in the proposed mechanism explains the increased potency found with increased dietary or water sulfide intakes.

Bray et al $^{(7)}$ found tri- and tetra-thiomolybdates to be the predominant species found in cultured rumen fluid. Using non-fermentation ruminal conditions, Clarke \& Laurie $^{(8)}$ showed the formation of the relative thiomolybdates to be $\mathrm{pH}$ - and $\mathrm{S}$ (given as sulfide):Mo molar ratiodependent. Clarke \& Laurie ${ }^{(8)}$ showed at $\mathrm{pH} 7 \cdot 0$ that molar S:Mo ratios of $<3$ only produced mono-thiomolybdates, 5-10:1 resulted in di-thiomolybdates, above 10 quickly transformed to tri-thiomolybdates, but found total conversion to tetra-thiomolybdate occurring at about 300:1. An S:Mo molar ratio of $62: 1$ at $\mathrm{pH} 8.0$ resulted in the dithiomolybdate being the predominant form (with no significant tetra-thiomolybdate), whereas at $\mathrm{pH} 6.5$ the tri form dominated, and as $\mathrm{pH}$ decreased the tetra-thiomolybdate form increased. The modern dairy cow has a much lower ruminal $\mathrm{pH}$ than the older-type hay-fed dairy cow. They also reported S:Mo ratios found in the field and in supplementation trials to range from 6:1 up to 8000:1, suggesting that many field conditions would produce mainly tetra-thiomolybdates. Bray et al. ${ }^{(9)}$ showed that the actual thiomolybdate production in rumen fermentation conditions, especially the production of tetra-thiomolybdate, was much greater than the Clarke \& Laurie ${ }^{(8)}$ work predicted. A third of molybdate was found to be converted to tetra-thiomolybdate over a wide range (4-12 $\mu \mathrm{g}$ Mo per $\mathrm{ml}$ ) of Mo inputs and at S:Mo molar ratios of $<10$. The molar ratios of $\mathrm{S}$ :Mo required for production of the tetra-thiomolybdate in this fermentative culture system were much lower than Clarke \& Laurie ${ }^{(8)}$ found for their non-fermentation culture. The system used by Clarke \& Laurie $^{(8)}$ was also a closed system with no removal or binding of the product produced and was therefore allowed to come to equilibrium.

Incubations of sieved (through a $0.9 \times 0.9 \mathrm{~mm}$ muslin mesh) rumen fluid (from cattle fed no Mo) with molybdate $(0.1 \mathrm{~mm})$ and sulfate $(2.4 \mathrm{~mm})$ by Elgallad et al ${ }^{(10)}$ resulted in the production of an absorption spectra indicative of tetra-thiomolybdate (239, 317 and $467 \mathrm{~nm}$ ) with no peaks indicative of di- or tri-thiomolybdates (392 and $394 \mathrm{~nm}$ ), indicating that only tetra-thiomolybdate was produced in significant amounts. However, when $\mathrm{Cu}$ was added to the culture before the incubation there was no evidence of tetra-thiomolybdates in the rumen fluid culture. Transferring their work into the whole animal, Elgallad et al. ${ }^{(10)}$ showed that in cattle fed $100 \mathrm{mg}$ Mo per kg DM, $3 \mathrm{~g} \mathrm{~S}$ per $\mathrm{kg}$ DM and $200 \mathrm{mg} \mathrm{Cu}$ per kg DM, there was no TCA-insoluble $\mathrm{Cu}$ and little albumin-bound $\mathrm{Cu}$. However, when $\mathrm{Cu}$ was reduced to $1 \mathrm{mg} / \mathrm{kg}$ DM the TCA-insoluble $\mathrm{Cu}$ content increased and greater than $80 \%$ of this was associated with albumin, $\mathrm{Mo}$ and $\mathrm{Cu}$; the caeruloplasmin concentrations were also reduced. When a $\mathrm{Cu}$ injection was given to these low-Cu ( $1 \mathrm{mg} / \mathrm{kg}$ DM)-fed cattle, the plasma $\mathrm{Cu}$ increased, as did the plasma Mo, and both the total 
amount and proportion of $\mathrm{Cu}$ in the TCA-insoluble fraction were increased.

The mechanism by which the thiomolybdates are formed is a stepwise dehydrolysis of molybdate with an $O$ being replaced by an $\mathrm{S}$ from a sulfide donor at each stage, the $\mathrm{O}$ being released as a water molecule ${ }^{(11)}$. This reaction is reversible and equilibria are temperature and $\mathrm{pH}$ dependent. The formation is outlined in Fig. 2.

The study by Price et $a l^{(12)}$ in which a large dose of ${ }^{99}$ Mo-labelled tetra-thiomolybdate was administered intraruminally and ${ }^{99}$ Mo-labelled tri- and di-thiomolybdates were recovered from the rumen digesta indicated the reversibility of this reaction in the rumen.

Whether the thiomolybdates are associated with the liquid or the solid phase of the rumen digesta is also of importance, as association with the solid phase imparts some stability on the thiomolybdates formed in the rumen, whereas the thiomolybdate in the liquid phase when remaining unbound, or unabsorbed is readily hydrolysed, reversing the reaction outlined above ${ }^{(12)}$. Available $\mathrm{Cu}$ within the digesta is also largely associated with the solid phase ${ }^{(12)}$, therefore potentially facilitating the intraruminal formation of $\mathrm{Cu}$-thiomolybdate complexes.

It is doubtful that the equilibria are reached under rumen conditions due to the availability of the substrates, molybdate and $S$ (as sulfide, or after rumen bug conversion to sulfide), along with the constant removal of the tetra-thiomolybdate. Therefore the reaction is most probably driven to the constant formation of thiomolybdates. The tetra-thiomolybdate would seem to have the following potential fates: (1) absorbed through the rumen wall; (2) passed
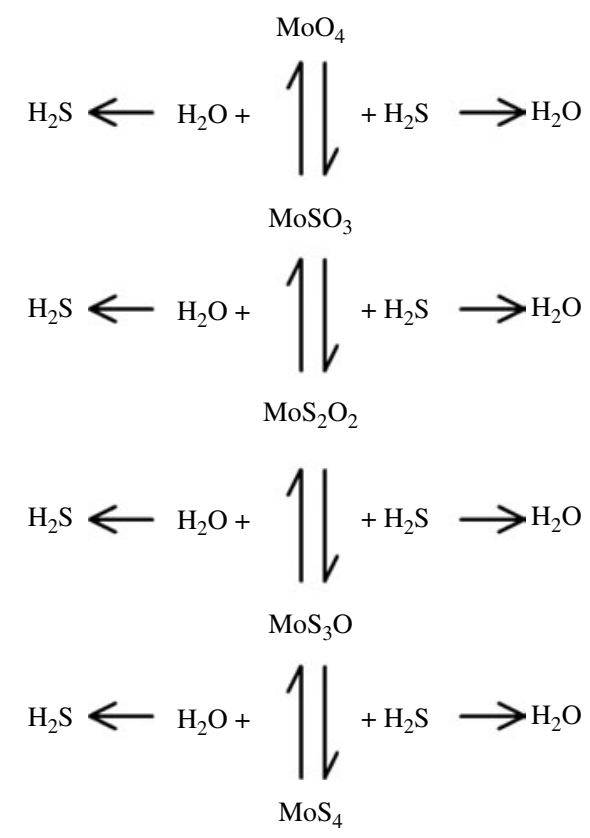

Fig. 2. Reactions that occur to form thiomolybdate in the rumen. The reactions are reversible. The direction is driven by the availability of molybdate and sulfide and the removal of the formed thiomolybdates by absorption and binding to the solid phase of forming the copper thiomolybdate complex within the rumen. with digesta through to the abomasum; (3) intra-ruminally bound to $\mathrm{Cu}$, forming insoluble copper thiomolybdates which are egested; (4) bound to the solid phase which seems to incur some chemical stability; (5) hydrolysed in the liquid phase (i.e. involved in the equilibria). This makes this a very dynamic system.

\section{Do thiomolybdates transfer into the animal and how?}

Kelleher et $a l .{ }^{(13)}$ showed that ${ }^{99}$ Mo-radiolabelled tetraand tri-thiomolybdates administered directly into the rumen of sheep by stomach tube appear within the plasma within $5 \mathrm{~min}$, mainly in a TCA-insoluble form. However, when ${ }^{99}$ Mo-radiolabelled molybdate was administered by the same route, only small traces were found in the plasma over the first $60 \mathrm{~min}$, with these predominantly in the TCA-soluble plasma fraction; after $2 \mathrm{~h}$ the amounts of ${ }^{99} \mathrm{Mo}$ in the plasma increased rapidly and from $4 \mathrm{~h}$ the radiolabel was predominantly in the TCA-insoluble fraction, suggesting that appearance of the label into the TCA-soluble or -insoluble fraction is rate dependent rapid uptake from a large ruminal thiomolybdate dose gives a large insoluble TCA fraction, whereas a slower digestive trickle feed gives more in the TCA-soluble fraction. Further, this indicates that more of the thiomolybdate from the large dose appears in plasma in a non-proteinbound form, whereas the trickle dose results in a greater proportion of the thiomolybdate being protein bound. The trickle dose of thiomolybdates gives 'free' or 'rumenavailable' Cu much more opportunity to 'detoxify' the thiomolybdates. It must be remembered that the above effects are ruminal, as these sheep had duodenal re-entrant cannulae fitted, which allowed the digestion and absorption from the rumen to be totally separate from the intestinal digestion and absorption, as digesta was exchanged between the rumen output of one sheep and the duodenal input of the partner sheep and vice versa. Initially after starting to receive the exchange digesta, the proportion of TCA-soluble ${ }^{99} \mathrm{Mo}$ in plasma for both tetra- and trithiomolybdate for the rumen administered/duodenal absorbed sheep was increased in comparison with the rumen administered/rumen absorbed partner (first $80 \mathrm{~h}$ ), but the TCA-insoluble fraction was similar after $30 \mathrm{~h}$. For the molybdate-administered sheep the digesta-exchanged sheep had virtually entirely TCA-soluble ${ }^{99}$ Mo for the first $4 \mathrm{~h}$, but between 4 and $6 \mathrm{~h}$ the TCA-insoluble fraction increased rapidly but to only half of the level of the TCA-soluble fraction. The TCA-soluble fraction declined more rapidly than the TCA-insoluble fraction.

Hynes et al. ${ }^{(14)}$ showed, using ${ }^{99}$ Mo-labelled molybdate administered to cattle, that there was maximal plasma concentration of labelled Mo after $20 \mathrm{~h}$, although similar to Kelleher et al. ${ }^{(13)}$ this was initially mainly in the TCA-soluble fraction and the TCA-insoluble fraction lagged behind but remained more persistent as the TCA-soluble labelled Mo declined. Hynes et al. ${ }^{(14)}$ also showed that protein-bound 
${ }^{99}$ Mo-labelled compounds were present. They eluted this protein with unlabelled tetra-thiomolybdate and displaced significant proportions of $\mathrm{di}$ - and tri-thiomolybdate and trace amounts of molybdate. They were unable to elute any tetra-thiomolybdate using this technique; however, whether this was as none was present or that unlabelled tetra-thiomolybdate was unable to displace the labelled tetra-thiomolybdate (both would have similar affinities) remains unclear. Mason et al. ${ }^{(15)}$ showed similar effects in sheep with no apparent production of tetra-thiomolybdate; however, they used the same elution technique and no account was made of the $\mathrm{Cu}$ content of the animal or diet.

In steers either given or not given a $\mathrm{Cu}$ injection immediately before an injection of radiolabelled tri-thiomolybdate, the steers with the $\mathrm{Cu}$ injection had virtually all of the radiolabel remaining in the plasma, whereas the steers not injected with $\mathrm{Cu}$ only had $40-50 \%$ of the administered radiolabel (from tri-thiomolybdate) in the plasma (mainly in the TCA-insoluble fraction) ${ }^{(14)}$. Price et $a l^{(12)}$ from their own and the work of others (discussed above) concluded that tetra-thiomolybdate was produced in the rumen, but remained absent from the liquid fraction and available for absorption until the solid fraction became saturated. The liquid fraction was the supernatant fraction of strained rumen fluid (through a single layer of muslin) after centrifugation at $2200 \mathbf{g}$, the solid fraction being the fine particulate material. The saturation of the solid fraction is probably related to the ruminally available $\mathrm{Cu}$ content of the solid fraction and this is at least partially shown by the $\mathrm{Cu}$ supplementation in the work of Hynes et al. ${ }^{(14)}$ discussed above. This is supported by work by Price \& Chesters $^{(16)}$ that showed available $\mathrm{Cu}$ in the digesta to be mainly in the solid phase of the rumen fluid. It is further supported by the tetra-thiomolybdate having a greater affinity for $\mathrm{Cu}$ and therefore the tetra-thiomolybdates will react with available $\mathrm{Cu}$ before the tri- and subsequently di-thiomolybdates and therefore not be available for absorption whereas the less reactive species are. Price et al. ${ }^{(12)}$ showed the presence of Cu(I)tetra-thiomolybdate $\left(\mathrm{CuS}_{2} \mathrm{MoS}_{2} \mathrm{Cu}\right)$ in rumen digesta as well as $\mathrm{Cu}(\mathrm{I})$ trithiomolybdate and $\mathrm{Cu}(\mathrm{I})$ di-thiomolybdate. This $\mathrm{Cu}(\mathrm{I})$ tetra-thiomolybdate was also found to have completely exchangeable tetra-thiomolybdate given excess copper iodide.

Suttle \& Field ${ }^{(17)}$ also concluded that tetra-thiomolybdates caused effects of $\mathrm{Cu}$ and Mo antagonism, whereas the di-thiomolybdate was shown not to play an important role in the $\mathrm{Cu}$ and Mo antagonism.

\section{What effects do absorbed thiomolybdates have in the animal?}

Chidambaram et al. ${ }^{(18)}$ showed tetra-thiomolybdate to inhibit in vitro all of the following $\mathrm{Cu}$-containing oxidase enzymes (value in parentheses is the concentration of tetra-thiomolybdate required for $50 \%$ inhibition): caeruloplasmin ( $p$-phenylenediamine $3.0 \mu \mathrm{M}$; o-dianisidine $2.7 \mu \mathrm{M})$; cytochrome oxidase $(2.0 \mu \mathrm{M})$; superoxide dismutase $(5.0 \mu \mathrm{M})$; ascorbate oxidase $(1.0 \mu \mathrm{M})$; tyrosinase (dopachrome formation $3.0 \mu \mathrm{m}$, catecholase acivity $4.5 \mu \mathrm{m})$. These levels of inhibition are physiologically relevant. Phillippo et $a l .{ }^{(19)}$ measured plasma Mo concentrations ranging from below the detection limit of $0.015 \mu \mathrm{g} / \mathrm{ml}(0.156 \mu \mathrm{m})$ for control and Fe-supplemented treatments up to $0 \cdot 16 \mu \mathrm{g} / \mathrm{ml}$ $(1.67 \mu \mathrm{M})$ for Mo-supplemented groups which would indicate that these levels could potentially be achieved in plasma, with the large caveat that it is not possible to show how much of the plasma Mo is in the form of thiomolybdates.

Chidambaram et al. ${ }^{(18)}$ also showed using atomic absorption that caeruloplasmin and tetra-thiomolybdatetreated caeruloplasmin both contained six coppers, i.e. tetra-thiomolybdate does not remove $\mathrm{Cu}$ from caeruloplasmin to inactivate it. The tetra-thiomolybdate was suggested to bind to the caeruloplasmin through the sulfide $(-\mathrm{S})$ groups, reducing the $\mathrm{Cu}$ (II) to $\mathrm{Cu}$ (I) (Fig. 3).

Chidambaram et al. ${ }^{(18)}$ also showed that, on a mole basis, ten tetra-thiomolybdate molecules bind to each caeruloplasmin, which suggests that some non-specific binding of tetra-thiomolybdate to caeruloplasmin must also occur; this had been previously shown to occur with non-specific binding of tetra-thiomolybdate to albumin. This reaction was reported to be irreversible. However, both Hynes et $a{ }^{(14)}$ and Lannon \& Mason ${ }^{(20)}$ reported reversibility of tri- and tetra-thiomolybdate effects both in vivo and in vitro. In vitro, Lannon \& Mason ${ }^{(20)}$ showed the reaction to reverse after gel filtration of the plasma, whilst in vivo the reaction began to reverse on cessation of the tetrathiomolybdate infusion.

Lannon \& Mason ${ }^{(20)}$ showed that infusion of tetraand tri-thiomolybdates both reduced the caeruloplasmin $p$-phenylenediamine oxidase activity and TCA solubility of $\mathrm{Cu}$, with the tetra form more potent than the tri form. They also found an increase in $\mathrm{Cu}$ associated with albumin. The reaction was apparently reversible, as full $p$-phenylenediamine oxidase activity of caeruloplasmin returned in vitro after gel filtration of the plasma, and in vivo as activity began to return upon cessation of thiomolybdate infusion. It was also noted that during infusion the total $\mathrm{Cu}$ content of the blood increased ( $24 \%$ over $24 \mathrm{~h}$ ); however, there was no reduction in caeruloplasmin $\mathrm{Cu}$ associated with the increased $\mathrm{Cu}$, which is in agreement with Chidambaram et al. ${ }^{(18)}$ showing that $\mathrm{Cu}$ is not removed from the caeruloplasmin to reduce the enzymic activity. The increase in plasma $\mathrm{Cu}$ is something also shown by Kendall et al. ${ }^{(21)}$, who found the total $\mathrm{Cu}$ concentration of plasma to be increased by a continuous infusion of

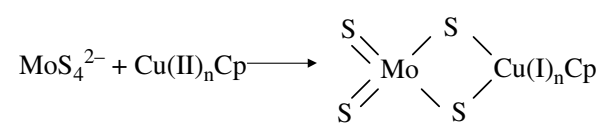

Fig. 3. Reaction for the binding of thiomolybdate to caeruloplasmin $(C p)^{(18)}$ 
$1 \mathrm{mg}$ tetra-thiomolybdate per $\mathrm{h}$ in sheep. By 1-week postcessation of infusion, thiomolybdate and control infused sheep had similar concentrations of plasma Cu. The TCAsoluble plasma $\mathrm{Cu}$ concentration remained consistent with the tetra-thiomolybdate infusion having a significant TCA-insoluble fraction. The caeruloplasmin $p$-phenylenediamine oxidase activity was also decreased by the tetrathiomolybdate infusion, but at the 1-week post-infusion sample full activity was regained. It was only the measure of whole blood superoxide dismutase activity which remained depressed at 1 week after cessation of the $5 \mathrm{~d}$ tetra-thiomolybdate infusion.

Kumaratilake \& Howell ${ }^{(22)}$ found in Cu-loaded sheep (fed $2 \%$ solution of copper sulfate at $10 \mathrm{ml} / \mathrm{kg}$ body weight for $5 \mathrm{~d}$ per week until a rise in alkaline phosphatase was observed) (range 55-149 d) that the administration of tetra-thiomolybdate ( $50 \mu \mathrm{g}$ intravenously twice per week) for 11 weeks significantly reduced liver $\mathrm{Cu}$ concentrations from 813.76 (SD 74.77) to 305.78 (SD 48.25) $\mathrm{mg} / \mathrm{kg}$ wet weight (ww); Cu concentrations also decreased in the non-thiomolybdate-treated controls but only to 594.57 (SD 104.29) $\mathrm{mg} / \mathrm{kg} \mathrm{ww}$. Also there were significantly increased liver Mo concentrations ( 0.93 to 87.25 (SD 16) $\mathrm{mg} / \mathrm{kg} \mathrm{ww}$ ) in the Cu-loaded animals.

Haywood et al. ${ }^{(23)}$ found a pituitary endocrinopathy in sheep associated with therapeutic administrations of thiomolybdates for the treatment of $\mathrm{Cu}$ toxicity. Williams et $a l .^{(24,25)}$ have shown similar effects in sheep feed Mo and $\mathrm{S}$.

\section{The role of iron: how does it react in the rumen?}

Phillippo et al. $^{(19,26)}$ showed Fe and S supplementation to reduce the blood plasma $\mathrm{Cu}$ content of cattle to hypocupraemic status $(1 \cdot 89-2.67 \mu \mathrm{M}$ and $3 \cdot 15-3.78 \mu \mathrm{M}$ compared with control group minimums of 10.54 and $15.73 \mu \mathrm{m}$ for two experiments, respectively; the internationally recognised threshold for $\mathrm{Cu}$ deficiency is $9.4 \mu \mathrm{M}^{(27)}$ ) without inducing the symptoms of 'clinical Cu deficiency' (reduced weight gain, decreased food intake, reduced efficiency of food conversion, alteration in hair texture, delayed puberty, reduced conception rate and inhibition of oestrus). Fe and Mo supplementation both reduced liver $\mathrm{Cu}$ and plasma $\mathrm{Cu}$ concentrations. Bremner et al. ${ }^{(28)}$ showed that Fe supplementation (4.5, 9 and $13.5 \mathrm{mmol} \mathrm{Fe} / \mathrm{kg} \mathrm{DM}$ ) had no effect on $\mathrm{Cu}$ status in preruminant calves, but decreased plasma and liver $\mathrm{Cu}$ when fed post-wearing although this did not induce a 'clinical' $\mathrm{Cu}$ deficiency until Mo was also fed. The effects of Fe and Mo were additive at the relatively low levels administered; previous trials with high supplement rates did not indicate an additive effect.

Campbell et al. ${ }^{(29)}$ showed Fe supplementation $(30 \mathrm{mg} /$ $\mathrm{kg}$ live weight) to reduce liver $\mathrm{Cu}$ from $179 \mathrm{mg} / \mathrm{kg} \mathrm{DM}$ down to $7 \mathrm{mg} / \mathrm{kg}$ DM, with plasma Cu concentrations starting to reduce after depletion of liver $\mathrm{Cu}$ to $40 \mathrm{mg} / \mathrm{kg} \mathrm{DM}$.
The Cu-dependent enzymes amine oxidase and caeruloplasmin were measured in this trial only after blood $\mathrm{Cu}$ had already been significantly reduced and were lower for the Fe-dosed group compared with the control group. These animals had a basal diet containing $1.5 \mathrm{mg} \mathrm{Mo} / \mathrm{kg}$ $\mathrm{DM}$ and $10.7 \mathrm{mg} \mathrm{Cu} / \mathrm{kg} \mathrm{DM}$.

No effect of high Fe supplementation ( $1 \mathrm{~g} / \mathrm{kg}$ diet) was noted on serum, liver or spleen $\mathrm{Cu}$ concentration by Rosa et $a l .{ }^{(30)}$; however, these sheep were being fed a low-S diet.

Standish \& Ammerman ${ }^{(31)}$ showed iron sulfate $(1.6 \mathrm{~g} / \mathrm{kg}$ Fe, $0 \cdot 28 \%$ sulfate) to significantly reduce the blood $\mathrm{Cu}$ concentration when compared with iron citrate $(1.6 \mathrm{~g} / \mathrm{kg} \mathrm{Fe})$ and no supplement. However, blood $\mathrm{Cu}$ concentrations when fed sodium sulfate $(0.28 \%$ sulfate $)$ were reduced but not significantly, and not to the degree that the iron sulfate reduced the blood $\mathrm{Cu}$ concentration.

In the rumen the $\mathrm{Fe}$ can react with sulfide and $\mathrm{Cu}$ either to produce an $\mathrm{Fe}-\mathrm{Cu}-\mathrm{S}$ complex which is not absorbed by the animal; an alternative hypothesis is that the Fe and sulfide combine to form an iron sulfide, and the $\mathrm{Cu}$ then exchanges with the Fe to form a copper sulfide (comment by C. F. Mills in Suttle \& Peter $\left.{ }^{(32)}\right)$. Both will therefore reduce the amount of $\mathrm{Cu}$ available within the rumen and will hence reduce the $\mathrm{Cu}$ available to participate in the Mo and $\mathrm{S}$ (thiomolybdate) and $\mathrm{Cu}$ interactions. However, there is little direct evidence in the literature to support either hypothesis, although what is clear is that there is an $\mathrm{Fe}-\mathrm{Cu}-\mathrm{S}$ interaction and it does decrease $\mathrm{Cu}$ availability.

\section{Sources of copper, molybdenum, sulfur and iron}

The complex interaction between these elements is explained above, but it is important to remember how these elements reach the rumen and in what form. The major routes of entry are in the diet and in the drinking water. The diet includes the elemental composition of the plant material consumed, dietary inclusion and supplements containing minerals (for example, mineral licks) and soil consumption, both as feed contamination and direct consumption. Soil can account for up to $25 \%$ of DM intake in certain situations; for example, in sheep grazing pasture with short grass either in very wet conditions (poaching) or with very dry and dusty conditions, where the annual soil consumption can exceed the live weight of the animal ${ }^{(33)}$. Other sources confirm this, with overwintered grazing cattle ingesting between 140 and $1400 \mathrm{~g}$ soil per $\mathrm{d}^{(34)}$. Drinking water can also be an important elemental entry route, whether it is mains water, spring water, stream water or from a borehole. Borehole water, especially, tends to be individual to the farm and can have a high sulfide content which as outlined above makes the $\mathrm{S}$ much more potent in the thiomolybdate formation reactions. The $\mathrm{Fe}$ in borehole water also often tends to be in the highly reactive ferrous form. 
Water-logging of soil in addition to increasing poaching and increasing soil consumption will also increase the uptake of Fe to plant material (four- to five-fold in young green shoots), with the Fe in the highly bioactive ferrous form $^{(29)}$. When soil (contamination) is ensiled with forages the fermentation process appears to increase the Fe bioactivity $^{(35)}$. The Mo uptake by plants, especially legumes, is also increased when grown in wet soils ${ }^{(36)}$. In general, Mo content is higher in vegetable protein supplements (for example, soya) and legumes (for example, clover $)^{(37)}$. Mo uptake is also increased with increasing $\mathrm{pH}$ of the soil (liming pasture increases Mo uptake) and generally increases throughout the growing season ${ }^{(37)}$. $\mathrm{S}$ tends to be related to protein concentration.

There are also differences found between continuous and discontinuous feeding on sulfide production ${ }^{(32)}$; this will also affect rumen $\mathrm{pH}$. Therefore, a continuous feeding system (for example, total mixed ration; TMR) will give a more consistent but moderately higher rumen $\mathrm{pH}$ with a stable sulfide content whereas a single or twice-daily feed will give a rapid decrease in rumen $\mathrm{pH}$ and peak production of sulfide, both of which will revert over time before the next meal.

\section{Summary}

Within the present review we have been able to provide evidence that: all classes of thiomolybdates are formed in the rumen; in the absence of available $\mathrm{Cu}$ all thiomolybdates can be absorbed into the animal rapidly though the rumen wall or more sedately via the small intestine; thiomolybdates can bind to $\mathrm{Cu}$ in biological compounds and are able to cause problems; effects of thiomolybdate are reversible in vivo and in vitro on cessation of thiomolybdate challenge; the tetra-thiomolybdate form is the most potent $\mathrm{Cu}$ binder with decreased potency with decreased $S$ in the compound. Fe will exacerbate a thiomolybdate problem but will not directly cause it.

\section{Acknowledgements}

This research received no specific grant from any funding agency in the public, commercial or not-for-profit sectors.

N. K. was the major contributor. L. G. had some small but significant input.

There are no conflicts of interest.

\section{References}

1. Laven RA \& Livesey CT (2005) The diagnosis of copper related disease, part 2: copper responsive disorders. Cattle Pract 13, 55-60.

2. Telfer SB, Kendall NR, Illingworth DV, et al. (2005) The diagnosis of copper related disease, part 2: copper responsive disorders. Cattle Pract 13, 284-286.

3. Laven RA \& Livesey CT (2006) Caeruloplasmin: plasma copper ratios in cows. Vet $\operatorname{Rec} \mathbf{1 5 9}, 608$.
4. Telfer SB, Kendall NR, Illingworth DV, et al. (2006) Caeruloplasmin: plasma copper ratios in cows. Vet Rec 159, 607-608

5. Moeini MM (1997) The effect of interactions between copper, molybdenum, iron and sulphur on metabolism and fertility in ruminant animals. PhD Thesis, University of Leeds.

6. Dick AT, Dewey DW \& Gawthorne JM (1975) Thiomolybdates and copper-molybdenum-sulfur interaction in ruminant nutrition. J Agric Sci 85, 567-568.

7. Bray AC, Suttle NF \& Field AC (1982) The determination of thiomolybdates in continuous cultures of rumen microorganisms. Proc Nutr Soc 41, A66-A66.

8. Clarke NJ \& Laurie SH (1980) Copper-molybdenum antagonism in ruminants. 1. Formation of thiomolybdates in animal rumen. J Inorg Biochem 12, 37-43.

9. Bray AC, Suttle NF \& Field AC (1982) The formation of tri-thiomolybdates and tetra-thiomolybdates in continuous cultures of rumen microorganisms and their adsorption onto fiber. Proc Nutr Soc 41, A67-A67.

10. Elgallad TT, Mills CF, Bremner I, et al. (1983) Thiomolybdates in rumen contents and rumen cultures. I Inorg Biochem 18, 323-334.

11. Harmer MA \& Sykes AG (1980) Kinetics of the interconversion of sulfido- and oxomolybdate(VI) species $\mathrm{MoO}_{\mathrm{x}} \mathrm{S}_{4-\mathrm{x}}^{2-}$ in aqueous solutions. Inorg Chem 19, 2881-2885.

12. Price J, Will AM, Paschaleris G, et al. (1987) Identification of thiomolybdates in digesta and plasma from sheep after administration of ${ }^{99}$ Mo-labelled compounds into the rumen. Br J Nutr 58, 127-138.

13. Kelleher CA, Ivan M, Lamand M, et al. (1983) The absorption of labeled molybdenum compounds in sheep fitted with reentrant cannulae in the ascending duodenum. J Comp Pathol 93, 83-92.

14. Hynes M, Woods M, Poole D, et al. (1985) Some studies on the metabolism of labeled molybdenum compounds in cattle. J Inorg Biochem 24, 279-288.

15. Mason J, Lamand M \& Kelleher CA (1982) The effects of duodenal infusion of tri- and dithiomolybdate on plasma copper and on the diamine oxidase activity of caeruloplasmin (EC 1.16.3.1) in sheep. J Comp Pathol 92, 509-518.

16. Price J \& Chesters JK (1985) A new bioassay for assessment of copper availability and its application in a study of the effect of molybdenum on the distribution of available $\mathrm{Cu}$ in ruminant digesta. Br J Nutr 53, 323-336.

17. Suttle NF \& Field AC (1983) Effects of dietary-supplements of thiomolybdates on copper and molybdenum metabolism in sheep. J Comp Pathol 93, 379-389.

18. Chidambaram MV, Barnes G \& Frieden E (1984) Inhibition of ceruloplasmin and other copper oxidases by thiomolybdate. J Inorg Biochem 22, 231-239.

19. Phillippo M, Humphries W, Atkinson T, et al. (1987) The effect of dietary molybdenum and iron on copper status, puberty, fertility and estrous cycles in cattle. J Agric Sci 109, 321-326.

20. Lannon B \& Mason J (1986) The inhibition of bovine ceruloplasmin oxidase activity by thiomolybdates in vivo and in vitro: a reversible interaction. J Inorg Biochem 26, 107-115.

21. Kendall NR, Illingworth DV \& Campbell BK (2005) The effect of an intra-venous infusion of thiomolybdate on copper status and ovarian function in sheep. In Proceedings of the 12th International Symposium on Trace Element Metabolism in Man and Animals (TEMA-12) Abstracts, p. 60 (poster P26) [M Bonham, EM Duffy, LB McAnena and JJ Strain, editors]. Coleraine, UK: University of Ulster.

22. Kumaratilake JS \& Howell JM (1989) Intravenously administered tetra-thiomolybdate and the removal of copper from the liver of copper-loaded sheep. I Comp Pathol 101, $177-199$. 
23. Haywood S, Dincer Z, Jasani B, et al. (2004) Molybdenumassociated pituitary endocrinopathy in sheep treated with ammonium tetrathiomolybdate. J Comp Pathol 130, 21-31.

24. Williams CL (2004) The effects of molybdenum, iron and sulphur on copper metabolism and physiology of sheep. PhD Thesis, Harper Adams University College.

25. Williams CL, Haywood S, Wilkinson RG, et al. (2005) The effects of dietary molybdenum, sulphur and iron on the pituitary gland trace element content and function. In Proceedings of the 12th International Symposium on Trace Element Metabolism in Man and Animals (TEMA-12) Abstracts, pp. 79-80 (poster P63) [M Bonham, EM Duffy, LB McAnena and JJ Strain, editors]. Coleraine, UK: University of Ulster.

26. Phillippo M, Humphries WR, Bremner I, et al. (1985) Molybdenum-induced infertility in cattle. In Proceedings of the Fifth International Symposium on Trace Elements in Man and Animals, pp. 176-180 [CF Mills, I Bremner and JK Chesters, editors]. Farnham Royal, UK: Commonwealth Agricultural Bureaux.

27. Radostits OM, Gay CC, Hinchcliff KW, et al. (2007) Veterinary Medicine - A Textbook of the Diseases of Cattle, Horses, Sheep, Pigs, and Goats. London: Saunders Elsevier.

28. Bremner I, Humphries WR, Phillippo M, et al. (1987) Ironinduced copper deficiency in calves: dose-response relationships and interactions with molybdenum and sulfur. Anim Prod 45, 403-414.

29. Campbell AG, Coup MR, Bishop WH, et al. (1974) Effect of elevated iron intake on the copper status in grazing cattle. NZ J Agric Res 17, 393-399.

30. Rosa IV, Ammerm CB \& Henry PR (1986) Interrelationships of dietary copper, zinc and iron on performance and tissue mineral concentration in sheep. Nutr Rep Int 34, 893-902.
31. Standish JF \& Ammerman CB (1971) Effect of excess dietary iron as ferrous sulfate and ferric citrate on tissue mineral composition of sheep. J Anim Sci 33, 481-484.

32. Suttle NF \& Peter DW (1985) Rumen sulphide metabolism as a major determinant of copper availability in the diets of sheep. In Proceedings of the Fifth International Symposium on Trace Elements in Man and Animals, pp. 367-370 [CF Mills, I Bremner and JK Chesters, editors]. Farnham Royal, UK: Commonwealth Agricultural Bureaux.

33. Healy WB (1974) Ingested soil as a source of elements to grazing animals. In Trace Element Metabolism in Animals - 2. Proceeding of the Second International Symposium on Trace Element Metabolism in Animals, pp. 448-450 [WG Hoekstra, JW Suttie, HE Ganther and W Mertz, editors]. Baltimore, MD: University Park Press.

34. Thornton I (1974) Biochemical and soil ingestion studies in relation to the trace-element nutrition of livestock. In Trace Element Metabolism in Animals - 2. Proceeding of the Second International Symposium on Trace Element Metabolism in Animals, pp. 451-454 [WG Hoekstra, JW Suttie, HE Ganther and W Mertz, editors]. Baltimore, MD: University Park Press.

35. Hansen SL \& Spears JW (2009) Bioaccessibility of iron from soil is increased by silage fermentation. J Dairy Sci $\mathbf{9 2}$, 2896-2905.

36. Kubota J (1975) Areas of molybdenum toxicity to grazing animals in western states. J Range Manag $\mathbf{2 8}$, 252-256.

37. Mills CF \& Davis GK (1987) Molybdenum. In Trace Elements in Human and Animal Nutrition, vol. 1, 5th ed., pp. 429-464 [W Mertz and EJ Underwood, editors]. London: Academic Press. 